Cahiers $d u$ MONDE RUSSE

\section{Cahiers du monde russe}

Russie - Empire russe - Union soviétique et États indépendants

$46 / 4 \mid 2005$

L'invention d'une politique humanitaire

\title{
Leonid Livak, Gervaise Tassis, éds., Le Studio franco-russe
}

Michel Aucouturier

\section{OpenEdition}

Journals

Édition électronique

URL : https://journals.openedition.org/monderusse/6676

DOI : 10.4000/monderusse.6676

ISSN : $1777-5388$

Éditeur

Éditions de l'EHESS

Édition imprimée

Date de publication : 1 décembre 2005

Pagination : 989-990

ISBN : 2-7132-2057-2

ISSN : $1252-6576$

Référence électronique

Michel Aucouturier, "Leonid Livak, Gervaise Tassis, éds., Le Studio franco-russe », Cahiers du monde russe [En ligne], 46/4 | 2005, mis en ligne le 30 juin 2009, consulté le 03 septembre 2022. URL : http:// journals.openedition.org/monderusse/6676; DOI : https://doi.org/10.4000/monderusse.6676

Ce document a été généré automatiquement le 3 septembre 2022

Tous droits réservés 


\title{
Leonid Livak, Gervaise Tassis, éds., Le Studio franco-russe
}

\author{
Michel Aucouturier
}

\section{RÉFÉRENCE}

Leonid LIVAK, Gervaise TASSIS, éds., Le Studio franco-russe. Textes réunis et présentés par Leonid Livak. Sous la rédaction de Gervaise Tassis.Toronto : Toronto Slavic Library, 2005, $621 \mathrm{p}$.

« Studio franco-russe » est le nom qu'un jeune poète et romancier français issu du cercle de Jacques Maritain, Robert Sébastien (né en 1903) et un jeune émigré russe, ancien combattant de l'Armée blanche devenu journaliste à l'Intransigeant, Wsevolod de Vogt (ou Vsévolod Fokht, 1895-1941) ont choisi pour organiser, sous l'égide du mouvement rénovateur Humanités contemporaines de J. Probus-Corréard, l'un des directeurs de l'Intransigeant et le fondateur de la revue France et Monde, des séances de débats publics destinées à favoriser les contacts entre l'émigration russe et la communauté intellectuelle française.

2 Ces débats mensuels se sont tenus régulièrement au cours de deux saisons, de novembre 1929 à mai 1930, puis de novembre 1930 à avril 1931, en présence d'un public nombreux, auquel les 300 places du Musée social, au 5 de la rue Las Cases à Paris, n'allaient souvent pas suffire. Les thèmes, proposés chaque fois à un conférencier russe et à un conférencier français, allaient être successivement : l'inquiétude dans la littérature, l'influence mutuelle des littératures française et russe, l'œuvre de Dostoevskij, de Tolstoj, de Proust, de Gide, le roman (français et russe) depuis 1918, la littérature soviétique, Paul Valéry, le symbolisme (français et russe), Descartes, Péguy, le renouveau spirituel (en France et en Russie). Parmi les orateurs, du côté français, René Lalou, Stanislas Fumet, Louis Martin-Chauffier, Benjamin Crémieux, Jacques Maritain; du côté russe, Nikolaj Berdjaev, Georgij Adamovič, Vladimir Weidlé, Nina Berberova, Georgij Fedotov, Boris Vyčeslav-cev. Dans la salle, intervenant parfois dans les débats, les Russes 
Nadežda Teffi, Georges Gurvitch, Mark Aldanov, Vasilij Maklakov, Lev Šestov, Nikolaj Ocup, Marina Cvetaeva, Boris Zajcev, Vladislav Hodasevič, Mark Slonim, Mihail Osorgin, Irina Odoevceva, Georgij Ivanov, Nikolaj Bahtin, Vladimir Pozner, Sergej Šaršun; du côté français Emmanuel Bove, Georges Bernanos, Pierre Bost, Charles du Bos, Gabriel Audisio, Denis Roche, Daniel Halévy, Luc Durtain, Robert Brasillach, et Paul Valéry luimême, au terme de la séance consacrée à son œuvre. Les principaux représentants de deux générations d'écrivains russes chassés de leur pays par la révolution ont ainsi pu se faire entendre par leurs collègues français et souvent établir avec eux de cordiales relations personnelles. Bien que celles-ci soient implicitement présentes à l'arrière-plan de la plupart des sujets évoqués (mais de façon explicite seulement dans le débat sur la littérature soviétique), les prises de position politiques sont soigneusement évitées.

Publiés de mois en mois par les Cahiers de la Quinzaine, les textes des conférenciers et les minutes des débats viennent d'être réunis dans un gros volume édité par l'université de Toronto, sous la rédaction de Gervaise Tassis, qui dirige le Groupe de recherches sur l'émigration de l'université de Genève. Auteur du premier ouvrage publié jusqu'à ce jour sur les liens de la littérature de l'émigration russe de l'entre-deux-guerres et son environnement littéraire parisien ${ }^{1}$, Leonid Livak, qui a réuni ces textes, analyse, dans une importante préface, les oppositions et les convergences que ces débats font apparaître entre " point de vue russe » et " point de vue français ». Mais il montre surtout comment, à cette confrontation, qui devait permettre aux uns et aux autres de mieux se connaître à travers leurs différences, se superpose d'emblée une opposition entre "anciens" et " modernes » des deux camps, et comment très vite les « modernes » se désintéressent des débats et désertent les réunions, où se fait de plus en plus sentir l'inflexion religieuse caractéristique et de l'émigration russe et d'une partie des cercles français que fascine une Russie qui est avant tout pour eux celle de Dostoevskij et de Tolstoj.

Les textes des conférences, et de la plupart des interventions qui les ont suivies, sont du plus haut intérêt. Outre leur valeur intrinsèque, ils nous apportent, par la qualité de leurs auteurs et la place que ceux-ci occupent dans la vie littéraire française et russe des années 1929-1930, un aperçu historique passionnant des préoccupations intellectuelles de l'époque et de la place qu'y tient la Russie.

5 L'ouvrage est opportunément complété par un dossier réunissant les comptes rendus que la presse russe de Paris a consacrés aux " soirées franco-russes ", et par de brèves notices sur tous les participants. Il éclaire ainsi de façon exhaustive un chapitre important des relations intellectuelles et littéraires entre les deux pays.

- Leonid Livak, How it Was Done in Paris: Russian Emigré Literature and French Modernism, Madison, WI :The University of Wisconsin Press, 2003, 316 p. 